Disponível em

http://www.anpad.org.br/rac

RAC, Rio de Janeiro, v. 17, n. 5, art. 3, pp. 556-573, Set./Out. 2013

$(\mathrm{cc})$ EY-NG

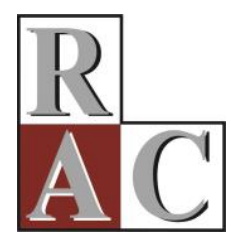

\title{
Wittgenstein e a Administração: Potencialidades da Pragmática da Linguagem aos Estudos Organizacionais e à Estratégia
}

Wittgenstein and Management: Potentialities of Linguistic Pragmatics to Organizational Studies and Strategy

Samir Adamoglu de Oliveira

E-mail: samiroliveira09@hotmail.com

Universidade Positivo - PMDA/UP

Rua Prof. Pedro Viriato Parigot de Souza, 5300, 81280-330, Curitiba, PR, Brasil.

Yára Lúcia Mazziotti Bulgacov

E-mail: ybulgacov@gmail.com

Universidade Positivo - PMDA/UP

Rua Prof. Pedro Viriato Parigot de Souza, 5300, 81280-330, Curitiba, PR, Brasil.

Artigo recebido em 26.02.2013. Última versão recebida em 30.07.2013. Aprovado em 02.08.2013. 


\title{
Resumo
}

Motivado pelos trabalhos de Mantere (2010), Mattos (2003a), e Schatzki (1996), o ensaio visa discutir quais as potencialidades que a noção wittgensteiniana de jogos de linguagem oferece para os Estudos Organizacionais (EOs) e para os estudos em Estratégia Organizacional (particularmente na vertente da Estratégia como Prática). Para isso: (a) explica-se a noção de jogos de linguagem, central na pragmática da linguagem do período maduro da filosofia de Wittgenstein; (b) analisam-se ideias dessa pragmática já versadas para a Administração, com ênfase particular a temas dos EOs e ao strategizing organizacional; e (c) enunciam-se as possibilidades analíticas e explicativas vislumbradas às áreas.

Palavras-chave: jogos de linguagem; práticas sociais; strategizing; Wittgenstein.

\begin{abstract}
Motivated by the work of Mantere (2010), Mattos (2003a) and Schatzki (1996), this essay aims to discuss the potentialities afforded by the Wittgensteinian notion of language games to Organizational Studies (OS) and Strategy Studies (particularly in the Strategy as Practice approach). In order to do this, the article: (a) explains the language games notion, which is fundamental to Wittgenstein's late-period philosophy; (b) analyzes linguistic pragmatic ideas already used in Management, particularly regarding themes of OS and strategizing; and (c) outlines the analytical and explanatory possibilities envisioned for these theoretical fields.
\end{abstract}

Key words: language games; social practices; strategizing; Wittgenstein. 


\section{Introdução}

Quais as possibilidades analíticas e explicativas que a noção wittgensteiniana de jogos de linguagem concede aos problemas subjacentes ao processo de formulação, elaboração e operacionalização vivida da estratégia organizacional (ou seja, ao strategizing organizacional), compreendidos segundo a vertente da Estratégia como Prática (Strategy as Practice), bem como a questões pertinentes aos Estudos Organizacionais na Administração?

Um problema de pesquisa introdutório como este, mais do que situar o leitor na proposta deste ensaio $^{(1)}$, visa instigá-lo a refletir não apenas sobre as possibilidades e aos potenciais explicativos dessa versátil e contemporânea abordagem teórico-metodológica de pesquisa ao tema da Estratégia Organizacional (Golsorkhi, Rouleau, Seidl, \& Vaara, 2010), mas também - e principalmente inquietá-lo sobre como uma noção associada a um pensamento dos mais densos e complexos da história da Filosofia pode ser convidada a dialogar e, porventura, auxiliar, no entendimento de questões empíricas do terreno científico interdisciplinar da Administração (Mattos, 2009). Tal empreendimento analítico-exploratório baseia-se num recorte particular para com parte da obra do filósofo austríaco Ludwig Joseph Johann Wittgenstein (1889-1951), a saber: os elementos concernentes à dimensão social e pragmática presentes na dita segunda fase ou período maduro da sua filosofia - na sua filosofia da linguagem ordinária, esboçada nas Philosophische Untersuchungen (Investigações Filosóficas).

Lançando as bases do que foi uma reviravolta linguística seguida de uma reviravolta pragmática (Oliveira, 2006), a filosofia da linguagem de Wittgenstein conflaciona linguagem, realidade e pensamento, a partir da forma como os seres humanos agem no cotidiano das suas vidas, aceitando como pressuposto que os limites para essas ações são os limites da própria linguagem humana (Reed, 2005; Rorty, 1994). Dessa maneira, a linguagem é entendida aqui como "ação, como sistemas de atos simbólicos, e não como representação mental ou sistema formal", de modo que, a partir disso, lida-se com a impossibilidade de se considerá-la como um todo completo e pleno, passando-se à necessidade de investigá-la em seus fragmentos, em suas áreas de discurso, em seus jogos de linguagem (Marcondes, 2000, pp. 53-54).

Oliveira (2006) afirma que a quantidade de material acerca da obra desse pensador já é considerada ampla, de modo que a menção desse recorte das ideias do filósofo vienense aqui pretendido e optado se faz necessária, para fins de esclarecimento das suas próprias implicações e limitações para o texto que se segue. É crucial, portanto, destacar que o foco de interesse e de apropriação das ideias de Wittgenstein que se seguirá no presente ensaio está nucleado em elementos e questões provenientes da sua pragmática da linguagem, e terão embasamento, em sua maioria, em leituras consideradas não ortodoxas da sua obra - ou seja, a partir de autores que evidenciam e exploram mais esses mencionados elementos socioculturais e pragmáticos do pensamento wittgensteiniano, e menos as questões lógico-linguísticas que marcaram o primeiro período da sua filosofia (representado pela obra Tractatus Logico-Philosophicus).

A influência do pensamento de Wittgenstein para além das ditas Ciências Humanas é notada nas Ciências Sociais, e, em particular, para o que se convencionou chamar, desde meados do século passado, de teoria social (Giddens \& Turner, 1999). Bernstein (2010), Oliveira (2006) e Schatzki $(1996,1997,2000,2001)$ são alguns dos autores que atestam que as ideias oriundas da obra madura de Wittgenstein são de influência crucial para o desenvolvimento do que se denomina, atualmente, de reviravolta da prática, em absorção contemporânea nas Ciências Sociais. Caracterizada por um retorno à razão prática, esta constitui uma tentativa de superar o antigo dualismo entre as visões do individualismo metodológico e da sociologia estrutural no entendimento dos fenômenos sociais, as quais polarizam suas explicações na ênfase exagerada à arbitrariedade da ação humana individual, ou ao determinismo da força das estruturas sociais, respectivamente (Schatzki, 2001).

Ao deslocar a atenção dos estudos em estratégia para tais contornos da prática, realizou-se uma retomada de ideias, concepções e noções explicativas de teóricos sociais, mas não apenas destes; das 
bases filosóficas das quais estes partiram, também (Rasche \& Chia, 2009). Dessa forma, a figura de Wittgenstein (2009) é direta ou indiretamente presente em boa parte das ideias que embasam a Estratégia como Prática (Strategy as Practice) (Golsorkhi et al., 2010), sendo a pragmática da linguagem, conforme elaborada na dita segunda fase da sua filosofia, de substancial relevância, principalmente quando compreendida aquela que aqui se julga ser sua noção capital: a noção de jogos de linguagem (Hadot, 2007; Oliveira, 2006).

Motivado principalmente por argumentos e sugestões de pesquisa presentes nos trabalhos de Mantere (2010), Mattos (2003a), e Schatzki (1996), o presente ensaio teórico tem por objetivo discutir quais as potencialidades que a noção wittgensteiniana de jogos de linguagem oferece tanto para os Estudos Organizacionais quanto para os estudos em Estratégia Organizacional, principalmente quando tomados a partir da vertente da Estratégia como Prática (Strategy as Practice). Para isso, o texto está estruturado da seguinte maneira: a segunda seção discutirá a noção de jogos de linguagem presente na pragmática da linguagem do período maduro da filosofia de Ludwig Wittgenstein, a qual se julga, aqui, ser ímpar para a tentativa de responder ao problema colocado; a terceira seção discutirá quais ideias, argumentos e/ou noções dessa filosofia já se encontram versadas para o campo interdisciplinar da Administração, com atenção especial aos Estudos Organizacionais e aos estudos em Estratégia Organizacional; por fim, serão enunciadas as possibilidades analíticas e explicativas que a noção wittgensteiniana de jogos de linguagem pode proporcionar não apenas ao conceito do strategizing organizacional - central para a vertente da Estratégia como Prática, mas também ao campo científico interdisciplinar da Administração, à luz das arguições elaboradas nas seções anteriores.

\section{A Pragmática da Linguagem de Ludwig Wittgenstein}

A obra de Wittgenstein costuma ser qualificada de maneiras distintas, independente de se comentada a partir de um ponto de vista filosófico ou científico. Fortemente vinculado à tradição analítica da Filosofia (pela estilística na qual se constrói, a qual preza pela arguição e proposição lógico-matemática como método fundamental para sua elaboração), seu pensamento é taxado de um dos mais complexos, densos, imprecisos, herméticos e até mesmo inacessíveis da história da Filosofia como um todo, fato este que atrai tanto quanto afasta, em quantidades generosas, aqueles que com ele entram em contato (Hadot, 2007; Marcondes, 2000; Oliveira, 2006).

Exemplo de que os movimentos do pensamento e da obra de um determinado autor são, inevitavelmente, reflexos dos movimentos da sua biografia (Monk, 1995), o trabalho de Wittgenstein passa, ao longo do seu desenvolvimento, por modificações, abandonos e rupturas que instigam, há décadas, discussões exegéticas e questionamentos das suas possibilidades e limites de investigação e apropriação (Oliveira, 2006). Em particular, ocorre entre Wittgenstein (2008) e Wittgenstein (2009) uma substituição da tematização do indivíduo na sociedade (isolado, desprendido, e antes analisado sob argumentos e métodos lógico-matemáticos), pelo indivíduo na comunidade (ou seja, inserido numa cultura, com pertencimento a um grupo, e agora analisado sobre argumentos pragmáticolinguísticos), a partir da problemática contextualizada entre linguagem, realidade e pensamento (Oliveira, 2006).

Conforme argumenta Oliveira (2006), Wittgenstein $(2008,2009)$ é figura central (juntamente com filósofos do pragmatismo norte-americano) (Bernstein, 2010), nas questões entre linguagem, realidade e pensamento, em dois momentos-chave da história da Filosofia. Num primeiro momento, mesmo ainda marcado por uma concepção representacionista (Wittgenstein, 2008), o filósofo levou ao limite a questão da relação entre linguagem e realidade, sob o pano de fundo lógico-linguístico, no qual, sendo todos os problemas filosóficos efetivamente problemas de linguagem, em que se analisando uma linguagem poder-se-ia chegar a enunciados bastante elementares, passíveis de serem emparelhados às sensações empíricas, de modo que tal linguagem analisada (em termos lógicos) espelharia a realidade (Rorty, 1994). Já num segundo momento (Wittgenstein, 2009), seu pensamento migra para uma noção na qual linguagem e realidade se fundem pragmaticamente, ou seja, com a 
linguagem não mais representando a realidade, mas constituindo-a (em seu objeto) a partir da sua utilização. Dessa forma, os dois momentos-chave que se destacam aqui são uma reviravolta linguística que prepara o terreno para uma reviravolta pragmática, ambas ocorridas ao longo dos séculos XIX e XX (Bernstein, 2010; Oliveira, 2006), cujas implicações e impactos foram (e seguem sendo) sentidos não apenas nas Ciências Humanas, mas igualmente nas Ciências Sociais (Schatzki, 2001).

Nessa vinculação entre linguagem e realidade, Wittgenstein (2009) não opera uma negação da realidade aludindo a um eventual idealismo linguístico, no sentido de que a realidade (matéria, concreta) se produziria ou se evanesceria a partir de um produto mental instruído pelas palavras, ou de uma ontologia espiritualista; mas sim de que ela se funde com seu objeto, ou seja, de que o discurso e o objeto do discurso se fundem um no outro (Bloor, 1996), numa ruptura de dualismos mediante uma noção circular, autorreferencial, ativa (no sentido performativo) e autocriativa (agêntica) (Bloor, 1996), oferecendo, assim, uma saída para impasses que permearam a história da Filosofia (Bernstein, 2010; Rorty, 1994; Schatzki, 1996), e que seguem a afligir, também, as Ciências Sociais (Giddens, 1979, 1984; Reed, 2005), a saber: as dicotomias entre mente e corpo; pensamento e movimento; teoria e prática; razão e emoção/paixão/afetos; estrutura e ação; voluntarismo e determinismo.

Essa fuga/rejeição de dualismos assume um pressuposto antirrepresentacionista da realidade, no qual "a ênfase na primazia das práticas sociais" não significa uma simples e mera inversão do binômio hierárquico tradicional entre teoria e prática, mas antes, defende ser crucial o entendimento das práticas sociais mediante as quais a teoria em si mesma emerge e é dependentemente constituída e reconstituída nas (e pelas) próprias práticas sociais do seu discurso (Bernstein, 2010, p. 220, tradução nossa).

O alicerce fundamental do período maduro da sua filosofia é a noção de que as atividades linguísticas e não linguísticas adquirem sentido e significado à medida que são pragmaticamente utilizadas, isso quer dizer, à medida que elas são empregadas adequadamente, seguindo certas regras, como que lances num jogo - por isso, um jogo de linguagem (Sprachspiel) (Glock, 1998; Wittgenstein, 2009). Para Wittgenstein, jogos de linguagem compreendem a totalidade formada pela linguagem e pelas atividades com as quais ela vem entrelaçada, de modo que as atividades linguísticas encontram-se interligadas com as atividades não linguísticas, estando "imersas em nossas formas de vida... nas práticas gerais de uma comunidade linguística" (Glock, 1998, p. 229), "no modo de agir comum dos homens" (Wittgenstein, 2009, §206), entrelaçando, assim, cultura, linguagem e visão de mundo a partir do discernimento de que "Ao investigar os jogos de linguagem, reconhecemos que somente é possível compreendê-los em sua utilização, e esta utilização os conecta com as formas de vida que os fundamenta" (Valle, 2003, pp. 100-101), pois o uso de um termo está sempre associado a base de conduta-padrão comum de uma comunidade, adquirindo seu significado de forma sempre contextualizada.

Fazendo uso de técnicas descritivas da gramática, Wittgenstein almejava expor o valor heurístico (ou seja, de descoberta) dos jogos de linguagem para o entendimento do mundo cotidiano, tanto que a exposição exemplificada de algumas espécies ou tipos de jogos de linguagem podem ser encontrados nos parágrafos $\$ 2, \S 8, \S 10, \S 15, \S 21, \S 27, \S 48, \S 53, \S 60, \S 64, \S 86, \S 143, \S 151, \S 556$ e $\$ 630$ de Wittgenstein (2009). Nesse exercício investigativo, entende-se estar diante de uma multiplicidade de possibilidades de jogos de linguagem (Wittgenstein, 2009), exemplificados na forma de jogos de linguagem científicos (que visam descrever as aparências de objetos, mensurá-los, relatar eventos ou fenômenos, especular sobre possibilidades de pesquisar, formar, formular, testar e/ou validar hipóteses, teoremas e teorias), jogos de linguagem artísticos (representar, interpretar, atuar, cantar, contar uma história ou narrativa, produzir algum tipo de objeto, artefato ou obra, tocar algum tipo de instrumento), jogos de linguagem religiosos (o ato de rezar ou de colocar-se em um momento de transe ou introspecção espiritual), jogos de linguagem cotidianos (as inúmeras atividades de caráter rotineiro e, por vezes, taxados de despretensiosos, como contar uma piada, cumprimentar conhecidos, agir de maneira cortês), jogos de linguagem morais (do tipo dar ordens e obedecê-las), e assim por diante (Dall'Agnol, 2006). 
Devido à sua rejeição a essencialismos que aludem a transcendentalismos na linguagem, obscurecendo-a (Hadot, 2007; Shotter, 2005; Valle, 2003; Wittgenstein, 2009), Wittgenstein (2009) não trabalha com definições conceitualmente precisas, mesmo para termos tão caros a sua filosofia (sendo linguagem e jogos de linguagem, apenas alguns deles). Mesmo assim, para uma melhor compreensão da noção de jogos de linguagem, Sluga (1996a) esclarece que a mudança na concepção de linguagem da época do Tractatus Logico-Philosophicus para a das Investigações Filosóficas deuse a partir do instante em que Wittgenstein se deu conta de que havia, de fato "várias linguagens diferentes com várias estruturas diferentes as quais poderiam servir a necessidades diferentes" (p. 17, tradução nossa). Dessa forma, a linguagem não poderia ser compreendida como uma estrutura unificada e fixa, mas sim consistia de uma multiplicidade de subestruturas mais simples, ou jogos de linguagem, sendo apenas alguns deles governados (ou regidos) por regras formal e expressamente claras e precisas, ao passo que outros são como estruturas mais "frouxas" (Sluga, 1996a, p. 19, tradução nossa).

Afirma-se, com isso, que a noção de linguagem em Wittgenstein é sumariamente social ${ }^{(2)}$, sendo (re)criada e sustentada mediante as práticas sociais que surgem a partir da forma como expressões linguísticas e não linguísticas vão sendo utilizadas cotidianamente (Glock, 1998). E, tal qual em um jogo, a linguagem possui suas regras constitutivas, provenientes da sua gramática ${ }^{(3)}$, que definem o que é correto ou faz sentido fazer, dentro de um determinado universo linguístico e não linguístico prático. A dimensão prática, portanto, corporifica o seguimento adequado de uma regra comunitariamente aceita (leia-se disso, que possui carga de sociabilidade em sua aceitação) (Wittgenstein, 2009), haja vista a importância de se dominar (e aperfeiçoar, mediante recorrência de uso) uma técnica, um jogo de linguagem - entendendo por técnicas, as atividades, ações e reações que tornam possível um dado funcionamento da linguagem.

Valle (2003) sintetiza os argumentos de sociabilidade, dimensão humana da linguagem, regras (e seu seguimento) e natureza prática dos jogos de linguagem, até aqui desenvolvidos:

a linguagem não é plenamente independente do homem, tampouco da comunidade de seus usuários... A vinculação entre significado e o uso, agora defendida, reclama a observação de três condições: a primeira diz respeito ao modo como as palavras são utilizadas; a segunda deve observar o contexto em que se empregam as palavras; e a terceira tem de atentar para as funções que elas devem desempenhar. São, portanto, o modo, o contexto e a função os elementos que constituirão a organicidade dos jogos de linguagem... Admitindo que na linguagem as palavras e as sentenças mostram seu significado por meio de seu uso e sabendo que a linguagem se presta tanto para expressar as realidades regulares, quanto aquelas não regulares, Wittgenstein reconhece ser necessária a existência de um conjunto de regras que permitem o ordenamento do uso. Tal necessidade é reconhecida porque não se pode admitir que um signo tenha, para alguns, um significado e, para outros, um significado diferente, ou que, sem nenhuma razão, em uma ocasião expresse algo e, em outra, algo totalmente distinto. Mas linguagem é diversa, é heterogênea... Os jogos de linguagem nasceram do reconhecimento da multiplicidade dos usos linguísticos. As regras, portanto, transformam-se no critério necessário para a distinção daquela multiplicidade de usos. O jogo de linguagem esclarece as condições do uso da linguagem em cada caso particular, evidenciando, também, a necessidade de saber que uma palavra ou um enunciado está sendo utilizado de tal maneira e não de outra (pp. 95-98, grifo nosso).

Da concepção de seguimento de regra (einer Regel folgen) em Wittgenstein (2009), é importante apontar que as "regras são normas de aplicação dos conceitos em diferentes jogos de linguagem" (Martínez, 2010, p. 39), não tomando essa concepção como sendo de algum tipo coercitivo ou homogeneizante para o comportamento humano. Tal noção em Wittgenstein (2009) é próxima de algo mais flexível do que o próprio termo regra pode sugerir, segundo entendimento de senso-comum (Holt \& Mueller, 2011; Martínez, 2010), o qual pode indicar algum tipo de padrão conformista de conduta praxiológica. Há, como apontado na citação anterior de Valle (2003), um elemento de consenso no seguimento de uma regra, no que tange à aceitação de determinadas atividades linguísticas e não linguísticas numa dada comunidade, proveniente da questão da 
regularidade (ou constância) dessas condutas, e da legitimidade que a isso se segue (Wittgenstein, 2009).

Contudo, ao considerar-se a natureza nem sempre consciente (ou discursivamente articulável) da multiplicidade de jogos de linguagem (Wittgenstein, 2009), entende-se que nem todas as ações humanas resultam de impulsos programados, conferindo, assim, a chance para que se possa sempre realizar uma ação (ou um movimento) dentro de um determinado jogo de linguagem que, ao mesmo tempo em que não transgrida suas regras, flexibilize-as, expandindo os limites da linguagem para novas possibilidades de uso (Giddens, 1984, 1999; Schatzki, 1996; Wittgenstein, 2009).

O caráter plural da noção de jogos de linguagem wittgensteiniana é acompanhado não apenas por essa concepção dinâmica de como seguir uma regra (ou um conjunto de regras em um determinado jogo de linguagem), mas também pelo entendimento que, atrelado aos jogos de linguagem, estão "os distintos modos de se apresentar no mundo" (Valle, 2003, p. 82), ou seja, as distintas formas de vida (Lebensform) possíveis (Wittgenstein, 2009). Como afirma Cavell (2003, p. 33, tradução nossa): "você não pode usar palavras para fazer o que nós fazemos com elas até que você seja introduzido nas formas de vida que as conferem o sentido e a forma que elas possuem nas nossas vidas". Disso decorre que o processo de aprendizagem e aprimoramento no domínio de uma técnica ou de uma determinada prática (o aprender a dominar um jogo de linguagem, o aprender a jogar um jogo de linguagem) é indissociável da questão de se estar, ao mesmo tempo, acessando, conhecendo, aprendendo, vivenciando e absorvendo uma determinada forma de vida. Explicando o entendimento adequado para esse termo wittgensteiniano, Dall'Agnol (2006) diz que, mesmo a noção de forma-devida não implicando relativismo sociocultural - pois é uma noção gramatical - ela refere-se, primordialmente, aos elementos que se partilham entre os membros de uma espécie viabilizando a comunicação e, portanto, não se trata de uma noção biológica, em seu sentido estrito.

De maneira complementar, Martínez (2010) indica que as formas de vida não deixam de ser orgânicas e coletivas, no sentido de configurarem reações básicas do homem; mas, ainda assim, não são simplesmente (ou exclusivamente) biológicas. São, acima de tudo, culturais, parte integrante da história natural do homem, compreendendo aqui o termo história natural como algo predominantemente antropológico:

A 'história natural do homem' é a história de um animal que forma convenções, que usa conceitos e linguagem, enfim, é a história de um animal cultural ... se a concepção de Wittgenstein de natureza humana não é predominantemente biológica, então, a fortiori, seu conceito de 'forma de vida' não é biológico, mas cultural. Não há somente uma 'forma de vida humana e uniforme', mas antes existem múltiplas 'formas de vida', características de diferentes culturas e épocas. É claro que essas 'formas de vida' humanas descansam na natureza biológica humana, assim como na natureza física do mundo que habitamos... Assim, as 'formas de vida' seriam algo próprio de um ser vivo (estão aí, como nossa vida), um conjunto de práticas estandardizadas com uma permanência relativa ... o naturalismo de Wittgenstein é antropológico e não biológico. Não se deve confundir 'história natural do homem', história de criaturas que usam a linguagem no âmbito de uma cultura, com a história biológica do ser humano ... as 'formas de vida' fazem com que nossa linguagem tenha sentido, e são algo que compartilhamos sem que tenhamos tomado uma decisão de fazê-lo (Martínez, 2010, pp. 63-64, grifo do autor).

Com isso, percebe-se que as formas de vida e o seguimento de regras são elementos que adquirem sentido de maneira complementar. Igualmente, as formas de vida e os jogos de linguagem são, também, complementares; lembrando, contudo, que aquelas (as formas de vida) são muito mais do que a aplicação da linguagem, constituindo, assim, "o ponto tangencial onde natureza e linguagem se tocam", onde "linguagem e práxis se constituem" (Martínez, 2010, p. 60). Não se faz relevante questionar sobre a primazia da linguagem ou da prática [seria nada mais do que reforçar o enfeitiçamento do mundo pela linguagem (Wittgenstein, 2009)], pois estas se constituem mutuamente no uso, na ação vivida. $\mathrm{E}$, uma vez que não conseguimos escapar da linguagem, mesmo que para dela falarmos - ou seja, uma vez que somos constituídos na e pela linguagem, sempre 
falamos dentro dos seus limites, nada podendo dizer do que está além desses limites (Wittgenstein, 2008).

Juntamente com a multiplicidade de jogos de linguagem existentes, está também a complexidade que esses possuem, no seu interior. Isso significa dizer que, sendo a noção de jogos de linguagem não redutível a um conjunto único e precisamente delimitado de comportamentos, tem-se a possibilidade de que vários jogos de linguagem se cruzem, formando uma rede virtualmente sem fronteiras de diversos jogos (em sua heterogeneidade) (Lyotard, 2008), assemelhados por algumas das práticas, técnicas e regras que os compõem.

Dessa maneira, o que se tem é a possibilidade de jogos de linguagem que guardam semelhanças de família (Familienähnlichkeit) entre si (Wittgenstein, 2009). Isso não significa dizer que todos os jogos de linguagem existentes (ou um conceito, por exemplo) sejam determinados por semelhanças de família, mas sim que pelo menos algumas ramificações de um determinado jogo (ou conceito) vinculam-se, necessariamente, mediante essas semelhanças, por se desenvolverem "em torno de um ou mais “centros de variação"' (Glock, 1998, pp. 326-327).

Decorre disso que, do momento em que se é iniciado em um determinado jogo de linguagem, até o momento em que se o domina, não se está apenas aprendendo uma prática (ou dominando uma técnica) (Wittgenstein, 2009), mas também se está possibilitando conhecer outros jogos de linguagem que podem guardar semelhanças com este que se domina, em termos das regras que os regem, e das práticas que os compõem, pois “o que chamamos 'proposições', 'linguagem', não é a unidade formal imaginada por mim, mas a família de estruturas mais ou menos aparentadas entre si" (Wittgenstein, $2009, \S 108)$. E, para que se possa compreender essa natureza complexa, diversa e múltipla dos jogos de linguagem, faz-se necessário ser introduzido a eles, conhecê-los, aprender a jogá-los, dominá-los, não apenas para que seja possível distinguir, no seu cerne, quais práticas os compõem - evitando assim, descrevê-los apenas acessando a sua gramática superficial, e nunca alcançando sua gramática profunda (Wittgenstein, 2009) - mas para que se possa ir "do paralelismo superficial ao paralelismo profundo" (Spaniol, 1989, p. 96), olhando-os, vivendo-os, jogando-os (Wittgenstein, 2009).

Assim, a noção wittgensteiniana de jogo de linguagem acaba sendo, afinal, uma espécie de noção tripartite, ou seja, composta por três outras noções (ou elementos) necessários para que se possa compreendê-la, a saber: seguimento de regras; formas de vida; e semelhanças de família. A seguir, discutem-se articulações de ideias oriundas da filosofia wittgensteiniana para enriquecimento na Administração, tomando por eixo central a noção de jogos de linguagem.

\section{Ideias Wittgensteinianas na Administração: Articulações Possíveis}

O ponto de partida para tornar possível a argumentação desta seção foi a realização de um extenso levantamento do estado da arte de pesquisas científicas na Administração, abordando a pragmática da linguagem wittgensteiniana. A janela temporal do levantamento compreendeu desde janeiro de 1990 até fevereiro de 2013. O principal interesse foi levantar e analisar não apenas ensaios sobre o tema neste campo científico interdisciplinar, mas, sobretudo, exemplos de pesquisas que efetivamente apreendessem empiricamente a noção de jogos de linguagem, tomada aqui como central para essa pragmática linguística.

No âmbito da Academia internacional, o parâmetro de seleção dos artigos tomou base nos periódicos científicos internacionais (de língua inglesa) da área de Administração, Ciências Contábeis e Turismo, classificados em fevereiro de 2010 com conceitos A ou B pela Coordenação de Aperfeiçoamento de Pessoal de Nível Superior (Capes), os quais tivessem foco nas áreas de: (a) Estudos Organizacionais (EOs); (b) Estratégia Organizacional; e/ou (c) Comunicação Organizacional (esta última área sendo considerada devido a especificidade do tema Linguagem). Estabelecido tal parâmetro, foram pesquisados ao todo 26 periódicos: Academy of Management Journal; Academy of 
Management Review; Administration \& Society; Administrative Science Quarterly; Administrative Theory \& Praxis; Communication Monographs; Communication Quarterly; Communication Studies; Communication Theory; European Management Review; Human Relations; International Journal of Management Review; Journal of Business Communication; Journal of Business and Technical Communication; Journal of Management; Journal of Management Studies; Long Range Planning; Management Communication Quarterly; Organization; Organization Science; Organization Studies; Organizational Research Methods; Qualitative Research in Organizations and Management: An International Journal; Strategic Management Journal; Strategic Organization; e The Communication Review.

Nesse levantamento, que optou preferencialmente por filtros de busca avançada, foram empregados como rótulos, a figurar em títulos, resumos e/ou palavras-chave, os seguintes termos: Wittgenstein; language game(s); language (in) use; ordinary language; wittgensteinian pragmatics. $\mathrm{O}$ resultado apontou 13 artigos, distribuídos da seguinte maneira: (a) nove deles (Astley \& Zammuto, 1992; Depeyre \& Dumez, 2008; Holt \& Mueller, 2011; Mauws \& Phillips, 1995; Powell, 2001, 2003; Shotter, 1996, 2005, 2006) apresentam proposições de pesquisa ou ensaios teóricos versando ideias, noções ou conceitos wittgensteinianos para questões e problemáticas da área da Administração, dos Estudos Organizacionais e/ou da área de Estratégia Organizacional; (b) dois deles (Barge, 1994; Kavanagh, 2010) apresentam pesquisas empíricas utilizando noções da pragmática da linguagem wittgensteiniana na área dos Estudos Organizacionais, particularmente na subárea da Comunicação Organizacional; e, (c) dois deles (Castor, 2007; Ran \& Duimering, 2007) apresentam pesquisas empíricas no tema do uso da linguagem nas organizações, mas que, apesar de citarem termos ou noções wittgensteinianas, não empreendem uma investigação empírica nessas bases.

Concernente à realidade brasileira, para compor este estudo, realizou-se um levantamento bibliográfico que contemplou: (a) nove periódicos científicos referenciais da área de Administração, Ciências Contábeis e Turismo classificados em fevereiro de 2010 com conceito A2, B1 ou B2 pela Coordenação de Aperfeiçoamento de Pessoal de Nível Superior (Capes), sendo eles: Brazilian Administration Review (BAR); Cadernos EBAPE.BR (FGV); Organizações \& Sociedade (O\&S); Revista de Administração Contemporânea (RAC Impresso e RAC Eletrônica); Revista de Administração de Empresas (RAE impresso e RAE eletrônica); Revista de Administração da Mackenzie (RAM); Revista de Administração Pública (RAP); Revista de Administração da USP (RAUSP Impresso e RAUSP-eletrônica); Revista Eletrônica de Administração (REAd); e, (b) os anais dos eventos EnANPAD, 3Es, EnEO e EnEPQ, em suas edições ocorridas desde 1998 até 2012.

Optando preferencialmente por filtros de busca avançada, foram empregados como rótulos a figurar em títulos, resumos e/ou palavras-chave, os seguintes termos: Wittgenstein; jogo(s) de linguagem; pragmática da linguagem; uso da linguagem; filosofia da linguagem; e linguagem ordinária. O resultado apontou dez artigos (dos quais dois deles - Mattos, 2001, 2008 - figuram em anais de eventos, e seguiram posteriormente para publicação em periódicos - no caso, Mattos, 2003a, 2009), sendo praticamente todos eles proposições de pesquisa ou ensaios teóricos versando algumas ideias, noções ou conceitos wittgensteinianos para questões e problemáticas da área da Administração. Trata-se dos trabalhos de: Amâncio (2009); Amâncio e Gonçalves (2007); Amâncio e Gonçalves (2010); Honório e Mattos (2007); e Mattos (2001, 2003a, 2003b, 2008, 2009, 2010).

Os resultados desses dois levantamentos, e a leitura crítico-reflexiva dos textos reunidos, sugerem que estudos de base empírica apreendendo metodologicamente elementos da pragmática da linguagem wittgensteiniana, em Estudos Organizacionais ou na área da Estratégia Organizacional, ainda não figuram substancialmente nos cenários internacional e nacional. Há, particularmente na área de Estudos Organizacionais, alguns casos que figuram como exemplos de pesquisa empírica da pragmática da linguagem wittgensteiniana - especificamente Barge (1994) e Kavanagh (2010); porém, estes carecem de detalhamentos e de clareza para com os tipos de métodos utilizados na apreensão de material empírico, e também para com a maneira como se realizaram as análises que neles constam. Para estudos empíricos que contemplem a área de Estratégia, nenhum exemplo figura na lista indicada, o que aponta para uma possibilidade de contribuição teórica que atende a várias das demandas de pesquisa elaboradas por Mantere (2010). No caso nacional, ao levar-se em conta a quantidade de 
documentos encontrados para o intervalo de tempo pesquisado, temos o indicativo de que mesmo a disseminação (ensaística) dessas ideias, noções ou conceitos wittgensteinianos no campo científico da Administração brasileira, ainda é incipiente e concentrada nos trabalhos dos pesquisadores Pedro Lincoln Carneiro Leão de Mattos e Jessé Alves Amâncio.

Com base nesse levantamento, afirma-se não serem muitos os artigos que se utilizam de pressupostos da filosofia de Wittgenstein (2009), e menos ainda aqueles que registram pesquisas empíricas realizadas a partir de ideias, argumentos ou noções extraídas da sua obra. Em boa parte das vezes, trata-se mais de apropriações ou utilizações en passant dessas ideias, do que discussões acerca dos seus limites e possibilidades analíticas e explicativas para o nosso campo de conhecimento.

Conforme notam Hatch e Cunliffe (2006), a noção wittgensteiniana de jogos de linguagem acaba sendo aquela mais apropriada aos Estudos Organizacionais e à Teoria das Organizações da Administração, ressoando, por exemplo, em questões como as de comunidades linguísticas das organizações (ou language communities), nas quais o trabalho é estruturado mediante a maneira como as palavras são usadas no contexto das vidas cotidianas dos seus membros, desenvolvendo vocabulários compartilhados, repertórios de gêneros comunicativos, estilos retóricos e persuasivos, metáforas ou outras formas distintivas de comunicação e de autoexpressão, as quais moldam as atividades realizadas dentro desses grupos, a partir das conversações e interações que ocorrem nesses contextos (Orlikowski \& Yates, 1994; Yates, Orlikowski, \& Okamura, 1999).

Astley e Zammuto (1992) realizam aquela que parece ser a primeira discussão publicada em um periódico relevante da Administração a fazer uso da noção wittgensteiniana de jogos de linguagem. Ao identificarem dois jogos de linguagem (o dos administradores profissionais, e o dos pesquisadores acadêmicos da Administração), Astley e Zammuto (1992) argumentam que a redução de impasses e dificuldades relacionais entre esses dois grupos, bem como as diferenças entre eles podem ser minimizadas (se não resolvidas) a partir da melhoria no esforço, na compreensão e no entendimento, por parte dos administradores profissionais, para com a (ou na) utilização simbólica e conceitual das teorias e explicações científicas propostas pelos pesquisadores acadêmicos da área dos Estudos Organizacionais.

Esse esforço "parece ser uma via de ação mais frutífera" (Astley \& Zammuto, 1992, p. 455, tradução nossa), pelo fato de se estar ensinando (ou desenvolvendo) dessa forma, aos administradores profissionais, a capacidade analítica do pensar e do refletir, diante de problemas que nunca serão os mesmos em todas as organizações. Dessa maneira, não se trataria de demandar mais pesquisa instrumental (de cunho prescritivo) dos acadêmicos da Administração, mas de salientar que os jogos de linguagem atendem a formas de vida distintas, que podem guardar semelhanças, e cujas regras os integrantes de distintos jogos podem, também, aprender, dominar e passar a jogá-los, desde que tenham interesse em vivenciar (participar), também daquela (outra) forma de vida.

A princípio, este texto de Astley e Zammuto (1992) já sugeria uma apropriação minimamente válida, não fosse a leitura que ambos realizaram, assemelhando-a ao que seriam dois paradigmas científicos kuhnianos (o dos administradores profissionais, e o dos pesquisadores acadêmicos da Administração). Por conta desse entendimento inapropriado para com a noção de jogos de linguagem, Mauws e Phillips (1995) teceram severa crítica a Astley e Zammuto (1992), apontando esse e outros descuidos decorrentes do mencionado equívoco interpretativo ${ }^{(4)}$. Para aqueles, Astley e Zammuto (1992) alargaram (ou forçaram) demasiadamente a noção de jogos de linguagem, a qual se circunscreve mais apropriadamente a comunidades bem menores (leia-se, grupos contextualizados), aplicando-o para campos tão amplos, e que congregam em si tantas práticas (sutilmente ou não) distintas, quanto os campos dos praticantes profissionais da Administração, e o campo dos pesquisadores acadêmicos dos Estudos Organizacionais (ou da Ciência das Organizações).

Se, sob uma acepção wittgensteiniana, as organizações "devem ser abordadas não como objetos, mas como processos, como realizações sociais contínuas que são sustentadas mediante constante interação" (Mauws \& Phillips, 1995, p. 332, tradução nossa), então a leitura operada por Astley e Zammuto (1992) não apenas restringia sobremaneira o potencial analítico e explicativo da noção de 
jogos de linguagem para com a captação de sutilezas e diferenciações linguísticas e não linguísticas de grupos, como também homogeneizava por demais a riqueza dessas distinções e nuances. Diante disso, as organizações, constituídas nessas realizações sociais contínuas, seriam:

produto de uma história complexa a qual produzira as regras e os movimentos de muitos jogos de linguagem que as caracterizaram... De uma perspectiva dos jogos de linguagem, os laços no tecido da organização são jogos de linguagem, e o uso de um termo (ou gesto, ou prática) é mediado pelo jogo de linguagem no qual ele ocorre. Significados, portanto, irão variar dentro de organizações - bem como de organização para organização - de maneiras imprevisíveis (Mauws \& Phillips, 1995, p. 332, tradução nossa).

É interessante perceber as triangulações explicativas que esse texto de Mauws e Phillips (1995) possui com Honório e Mattos (2007) e Mattos (2003a, 2009, 2010). Discorrendo sobre os jogos de linguagem da comunidade de acadêmicos e consultores na Administração, Mattos (2003a), assim como Mauws e Phillips (1995), também salienta as questões de legitimidade contextualizada que a circunscrição de determinados jogos de linguagem realiza numa comunidade. Para aquele, a tensão existente entre o meio acadêmico e a atividade de consultoria empresarial é produto de uma intenção equivocada de hierarquizar jogos de linguagem sustentados nesses dois campos, atribuindo superioridade a instituições, práticas e praticantes deles que são, por definição, de naturezas distintas. Com isso, as condições de qualidade e as justificativas de uso que legitimam o que acontece em cada um desses campos devem ser compreendidas em suas especificidades circunstanciais, ainda que aproximações dialógicas entre eles permitam críticas para aprimoramentos de determinados conjuntos de práticas assemelhadas (Mattos, 2003a). Similarmente para Mauws e Phillips (1995), tais processos de legitimação apoiam-se não em argumentos universais, mas na singularidade variável dos jogos de linguagem que são praticados em cada comunidade de pesquisa, pois o próprio tecido social que as constitui é, em certa medida, um tecido de jogos de linguagem complexo, moldado social e historicamente em movimentos mutuamente reforçadores.

O que certamente dizem as conclusões dos trabalhos de Mauws e Phillips (1995), e Mattos (2003a), é que, por guardarem semelhanças de família entre si, esses diversos jogos de linguagem do campo científico interdisciplinar da Administração (sendo os administradores profissionais, os consultores, e os acadêmicos, os seus praticantes principais, mas não os únicos) podem, sim, guardar similaridades entre si, possuírem pontos conexos e convergentes e manterem, portanto, interfaces de diálogo entre seus universos linguísticos. Entretanto, as questões que visam a integração entre eles são, não apenas pretensiosas, como também equivocadas, haja vista a natureza circunscrita dos processos de legitimação das práticas que os compõem (oriundas do uso da linguagem naquelas comunidades), bem como as formas de vida que abrigam essas práticas, e nas quais esses tantos jogos de linguagem encontram sustentação.

Não há, com isso, impossibilidade de se realizar movimentos entre esses universos linguísticos, menos ainda a necessidade de se afirmar exclusividade entre eles, pois os praticantes desses jogos de linguagem sempre podem aprender, dominar e passar a jogar (adicionalmente) outros jogos de linguagem, desde que em concordância com a intenção de vivenciar (ou participar) daquela (outra) forma de vida. São, por isso, conhecimentos provenientes de contextos diferentes, e que servem a propósitos diferentes, diante do fato deles terem sido construídos em realidades diferentes (Van De Ven \& Johnson, 2006).

Passando ao campo dos estudos em Estratégia Organizacional, Powell (2001, 2003), elabora uma análise conceitual sobre um construto central para essa área: o construto lógico da vantagem competitiva. Nessa arguição, o autor afirma ser esse construto um exemplo de um jogo de linguagem que define e delimita, claramente, o campo da Estratégia Organizacional dentro da Administração, pois aqueles que com esse construto trabalham não apenas posicionam o conceito de vantagem competitiva como sendo central para o entendimento da existência ou desaparecimento de organizações, como também validam, em suas práticas de pesquisa, uma série de pressupostos derivados da Economia, necessariamente se apropriando de termos porterianos, e de métodos quantitativos de pesquisa, por exemplo. 
Em uma exposição contundente, Mantere (2010) articula não apenas a relação que a noção wittgensteiniana de jogos de linguagem tem com os pressupostos da perspectiva da Estratégia como Prática, mas também demonstra, mediante a análise de exemplos, como essa noção pode explicar o processo de se fazer uma estratégia, em seus entendimentos linguísticos e não linguísticos. Na literatura tradicional sobre estratégia, acredita-se, por exemplo, que a formulação e a implementação de uma estratégia proposta fluem naturalmente entre os níveis hierárquicos; porém, conforme expõe Mantere (2010), os processos de negociação e articulação política da estratégia, entre os níveis hierárquicos de uma organização, adquirem sentido justamente ao considerarmos que, diante da multiplicidade de jogos de linguagem dos grupos que compõem uma organização, serão as semelhanças de família que propiciarão esse fluxo e aceitação legítima do que se estabelece como estratégico, numa organização.

Isso significa dizer que, numa pesquisa sobre estratégia organizacional: "um critério fundamental para se definir as fronteiras de um jogo de linguagem em particular é a concordância acerca do uso apropriado de conceitos na determinação das questões que transcorrem naquela realidade" (Mantere, 2010, p. 165, tradução nossa), diferenciando esses possíveis jogos de linguagem dentro de uma mesma organização justamente a partir das práticas e das regras que os compõem, as quais colaboram para a concretização da estratégia organizacional.

Mesmo assim, o autor aponta que toda e qualquer delimitação de fronteiras de um jogo de linguagem é algo sempre passível de questionamento, pois, levando-se em conta as semelhanças de família, jogos de linguagem aparentemente distintos podem não apenas ser interconectados, mas também inter-relacionados entre si, o que confere complexidade às causalidades explicativas do conceito do strategizing. Em outras palavras, será mediante o entendimento vivenciado dos jogos de linguagem da estratégia que se poderão enxergar, a partir das práticas sociais que os compõem, as razões de eficiência e eficácia (leia-se, os resultados e o desempenho organizacional) que definem o êxito de determinadas estratégias organizacionais, e outras não.

Entretanto, as causalidades que podem influenciar as práticas estratégicas de uma organização não se resumem, exclusivamente, àquelas que surgem e que são reproduzidas intraorganizacionalmente. Mantere (2010) explica que a noção de jogos de linguagem auxilia na compreensão da dinâmica entre os níveis institucional, organizacional e micro-organizacional da estratégia, seguindo a mesma linha de raciocínio já estabelecida por Mauws e Phillips (1995), acerca dos jogos de linguagem que, mais do que permearem o campo interdisciplinar da Administração, influenciam-se em distintos graus, por conta dos fluxos e afluxos entre os seus praticantes: os administradores profissionais, os consultores, e os acadêmicos.

Considerado isso, não apenas serão múltiplos os jogos de linguagem da estratégia dentro da organização, mas também na própria área da Estratégia Organizacional da Administração - a própria existência de teorias econômicas e sociológicas (Vantagem competitiva, Escolha Estratégica, Visão Baseada em Recursos, Teoria da Dependência de Recursos, Ecologia Populacional, Teorias de Alinhamento Estratégico e Governança Corporativa, Abordagem dos Stakeholders, Estratégia como Processo, Estratégia como Prática, etc.) para se explicar a estratégia nas organizações é um exemplo disso; cada uma dessas pode ser entendida como sendo um jogo de linguagem, mas que, evidentemente, todas possuem suas semelhanças de família. Dito de outra forma, o tema da Estratégia Organizacional é, seguindo essa linha de raciocínio, uma área da linguagem da Administração, um dentre seus vários jogos, sendo em si mesma fragmentada.

Além dessa possibilidade de análise multinível na qual a noção wittgensteiniana de jogos de linguagem pode auxiliar, Mantere (2010) enfatiza que, situações nas quais a discordância acerca do uso correto de uma linguagem em particular é forte, podem ser extremamente frutíferas para a pesquisa do strategizing, por razão das confrontações e comparações (de racionalidades, de práticas, de formas de vida, etc.) que surgem dessas circunstâncias. Por conta disso, dois caminhos para pesquisar questões do strategizing a partir de uma perspectiva wittgensteiniana são sugeridos: (a) aquele cujo foco seria em pesquisar arenas de concordância e discordância particulares acerca do uso de determinada linguagem da estratégia, tanto em níveis micro quanto em níveis (ou esferas) 
institucionais distintas, contemplando, assim, a difusão de linguagens entre os níveis institucional e organizacional, por exemplo (Machado-da-Silva \& Vizeu, 2007); ou (b) aquele que pretenderia articular mais apropriadamente as noções de semelhanças de família e de jogos de linguagem entre os jogos de linguagem da própria perspectiva da Estratégia como Prática, não focando tanto nas questões de discordância (ou de disputas discursivas), mas focando mais em questões de como esses jogos de linguagem (giddensiano, bourdieusiano, foucaultiano, heideggeriano, engeströmiano, bakhtiniano, narratológico, etnometodológico, institucionalista, das vertentes ditas críticas, dos estudos históricos, construcionista, construtivista, etc.) se apoiam e se fortalecem mutuamente, a partir das suas semelhanças de família terminológicas, teóricas e metodológicas, auxiliando na constituição daquilo que se pode chamar de a perspectiva teórico-metodológica da Estratégia como Prática.

\section{Considerações Finais}

A obra de Wittgenstein (2009) empreendeu, direta e indiretamente, fortes ataques a concepções tradicionais da Ciência, como as de validade de verdade, alcance e universalidade de teoremas e teorias, e também da legitimidade dos seus argumentos (Lyotard, 2008). Abraçar ideais e noções da sua obra não implica uma negação da possibilidade de se fazer Ciência, mas sim a possibilidade de se construir conhecimento balizado pelo método científico, que não sustenta as mesmas pretensões de validade de verdade e universalidade que figuram como pressupostos de Ciência moderna invocando, com isso, um estilo de pensamento alternativo (Chia, 2005). Crê-se, assim, que a noção de jogos de linguagem pode, sim, oferecer contribuições analíticas e explicativas aos Estudos Organizacionais e para o campo da Estratégia Organizacional, considerando que: a noção de jogos de linguagem, quando aplicada à Administração, deve ser entendida a partir da sua circunscrição às comunidades dos praticantes que compõem as diversas e diferentes esferas desse campo, a saber: os pesquisadores acadêmicos, os administradores profissionais (gestores, gerentes, diretores, CEOs, etc.), os consultores - ou seja, como sendo jogos de linguagem dentre muitos outros que compõem o tecido social da Administração, enquanto um campo interdisciplinar.

Tal indicativo pode lançar luz a impasses teóricos hoje presentes em discussões tanto do campo dos EOs quanto dos estudos em Estratégia (em particular na vertente da Estratégia como Prática), a saber: (a) as ainda imprecisas distinções entre organizing e strategizing; (b) a própria conceituação do que são práticas sociais, quando circunscritas ao contexto de uma organização, e aos grupos dentro delas; além da (c) necessidade de se compreender que tanto no campo prático, quanto no campo teórico da Administração, existem linguagens (no sentido mais plural possível) em coexistência, em conflito, em tensão, e não uma única e singular linguagem.

Adicionalmente, por demandar atenção ao modo (como uma linguagem é usada), ao contexto (no qual ela é praticada), e à sua função (em um contexto histórico e institucionalmente constituído), a pragmática da linguagem de Wittgenstein pode figurar como uma ferramenta heurística potencialmente válida para a análise cotidiana do ordinário nas organizações e para o ato de praticar a estratégia organizacional - o strategizing organizacional -, compreendendo-os como processos verbais e não verbais vivenciados de modo engajado pelos indivíduos naqueles contextos. Abordando-os como processos linguísticos, sugere-se aqui que essa pragmática da linguagem pode viabilizar acessar, por meio de elementos técnicos, funcionais e histórico-institucionais derivados desses três elementos pontuados (o modo, o contexto e a função da linguagem em uso), questões como: (a) consonâncias e dissonâncias entre gramáticas e formas de vida; (b) ambiguidades retóricas; (c) conflitos, tensões e disputas argumentativas ancoradas em relações hierárquicas de poder; e, (d) processos macroorganizacionais e influências institucionais no contexto organizacional por uma via de mutualidade constitutiva das linguagens praticadas nessas esferas, por exemplo.

O "ordinário da linguagem tem, para Wittgenstein, um valor extraordinário" (Valle, 2003, p. 108), pois nele, cotidiano (diferentemente de rotina) é sempre possibilidade (que se renova a cada dia) de se fazer (algo) diferente, de inovar, de realizar diferentemente as coisas. Se for no cotidiano que 
nascem soluções para os problemas nas organizações, então talvez não tenhamos de nos afastar tanto dele para enxergarmos e compreendermos, de maneira vivenciada e sensitiva, o que as tais atividades práticas efetivamente são ("não pense, mas olhe!" (Wittgenstein, 2009, §66)), nem tampouco tenhamos de nos esquecer de quem (ainda que haja algumas décadas de distância) pensou as bases dessa reviravolta que agora nos enfeitiça.

\section{Agradecimentos}

Este trabalho contou com o apoio financeiro da Coordenação de Aperfeiçoamento de Pessoal de Nível Superior (CAPES) para sua realização.

\section{Notas}

\footnotetext{
${ }^{1}$ Uma versão deste ensaio foi apresentada no VII Encontro de Estudos Organizacionais da ANPAD (EnEO), realizado de 20 a 22 de maio de 2012, em Curitiba/PR.

${ }^{2}$ Um exemplo que corrobora esse entendimento é a crítica wittgensteiniana à existência de algum tipo de linguagem privada (Privatsprache) (Wittgenstein, 2009), a qual sustenta que nosso vocabulário psicológico não é privado no sentido de exclusivo ao falante, ou àquele que das suas experiências e sensações privadas imediatas fala - sem, com isso, significar que a esfera mental ou psicológica seja irreal (Glock, 1998; Hadot, 2007; Martínez, 2010; Shotter, 2006, 2007; Sluga, 1996b; Valle, 2003; Williams, M. (1999). Wittgenstein, mind and meaning: toward a social conception of mind. London: Routledge). Dessa forma, por social, em Wittgenstein, toma-se aqui uma noção próxima ao termo alemão Zusammenhang, o qual designa tudo que "pertence ao âmbito da coexistência humana", entendendo coexistência humana, por sua vez, como sendo "a interdependência de vidas humanas que formam um contexto no qual cada um procede individualmente"; e é a esse referido contexto, que se denomina, aqui, sociabilidade (Schatzki, 1996, pp. 13-15, tradução nossa).
}

${ }^{3}$ Gramática, no sentido do período maduro da filosofia de Wittgenstein, é aqui entendida numa acepção bem mais ampla do que o sentido tradicional do termo denota, podendo significar as regras do emprego de uma palavra, o complexo de regras que constituem uma linguagem, ou ainda a explicação que se dá a essas regras (Spaniol, 1989).

${ }^{4}$ Importa mencionar que tanto Astley e Zammuto (1992) quanto Mauws e Phillips (1995) - bem como outros dos exemplos selecionados aqui - utilizam-se do termo conceito para designar jogos de linguagem. Isso evidentemente não invalida as análises e os argumentos desses trabalhos; porém, julga-se ser mais coerente abordar e entender jogos de linguagem como sendo uma noção, haja vista a rejeição de Wittgenstein para com essencialismos e transcendentalismos na linguagem (Hadot, 2007; Mantere, 2010; Oliveira, 2006; Shotter, 2005, 2006; Valle, 2003)

\section{Referências}

Amâncio, J. A. (2009, setembro). Aprendizagem na perspectiva da pragmática da linguagem. Anais do Encontro Nacional da Associação Nacional de Pós-Graduação e Pesquisa em Administração, São Paulo, SP, Brasil, 33.

Amâncio, J. A., \& Gonçalves, C. A. (2007, novembro). Uma proposta pragmática para se pensar o ensino na Administração. Anais do Encontro de Ensino e Pesquisa em Administração e Contabilidade, Recife, PE, Brasil, 1.

Amâncio, J. A., \& Gonçalves, M. A. (2010, setembro). Um modelo de racionalidade pragmática para a Administração. Anais do Encontro Nacional da Associação Nacional de Pós-Graduação e Pesquisa em Administração, Rio de Janeiro, RJ, Brasil, 34.

Astley, W. G., \& Zammuto, R. F. (1992). Organization science, managers, and language games. Organization Science, 3(4), 443-460. doi: 10.1287/orsc.3.4.443 
Barge, J. K. (1994). On interlinking language games: new opportunities for group communication research. Communication Studies, 45(1), 52-67. doi: 10.1080/10510979409368409

Bernstein, R. J. (2010). The pragmatic turn. Cambridge, UK: Polity Press.

Bloor, D. (1996). The question of linguistic idealism revisited. In H. Sluga \& D. G. Stern (Eds.), The Cambridge companion to Wittgenstein (pp. 354-382). Cambridge, NY: Cambridge University Press.

Castor, T. (2007). Language use during school board meetings: understanding controversies of and about communication. Journal of Business Communication, 44(2), 111-136. doi: $10.1177 / 0021943606298828$

Cavell, S. (2003). Excursus on Wittgenstein's vision of language. In A. Crary \& R. Read (Eds.), The new Wittgenstein (pp. 21-37). London: Routledge.

Chia, R. (2005). Organization theory as a postmodern science. In H. Tsoukas \& C. Knudsen (Eds.), The oxford handbook of organization theory (pp. 113-143). England: Oxford University Press.

Dall'Agnol, D. (2006). Jogos morais de linguagem. In A. R. Moreno (Org.), Wittgenstein: ética, estética, epistemologia (Coleção CLE, Vol. 43, pp. 59-79). Campinas: UNICAMP.

Depeyre, C., \& Dumez, H. (2008). What is a market? A Wittgensteinian exercise. European Management Review, 5(4), 225-231. doi: 10.1057/emr.2008.25

Giddens, A. (1979). Central problems in social theory: action, structure and contradiction in social analysis. Berkeley and Los Angeles: University of California Press.

Giddens, A. (1984). The constitution of society: outline of a theory of structuraction. Berkeley and Los Angeles: University of California Press.

Giddens, A. (1999). Estruturalismo, pós-estruturalismo e a produção da cultura. In A. Giddens \& J. Turner (Orgs.), Teoria social hoje (pp. 281-319). São Paulo: Editora UNESP.

Giddens, A., \& Turner, J. H. (1999). Introdução. In A. Giddens \& J. Turner (Orgs.), Teoria social hoje (pp. 7-21). São Paulo: Editora UNESP.

Glock, H. J. (1998). Dicionário Wittgenstein. Rio de Janeiro: Jorge Zahar Editor.

Golsorkhi, D., Rouleau, L., Seidl, D., \& Vaara, E. (2010). Introduction: what is strategy as practice? In D. Golsorkhi, L. Rouleau, D. Seidl, \& E. Vaara (Eds.), Cambridge handbook of strategy as practice (pp. 1-20). Cambridge: Cambridge University Press.

Hadot, P. (2007). Wittgenstein y los límites del lenguaje. Valencia, España: Pre-Textos.

Hatch, M. J., \& Cunliffe, A. L. (2006). Organization theory: modern, symbolic, and postmodern perspectives ( $2 \mathrm{a}$ ed.). New York: Oxford University Press.

Holt, R., \& Mueller, F. (2011). Wittgenstein, Heidegger and drawing lines in organization studies. Organization Studies, 32(1), 67-84. doi: 10.1177/0170840610394299

Honório, J. B., \& Mattos, P. L. C. L. (2007, setembro). Papéis organizacionais: o que a pragmática da linguagem nos leva a pensar. Anais do Encontro Nacional da Associação Nacional de PósGraduação e Pesquisa em Administração, Rio de Janeiro, RJ, Brasil, 31.

Kavanagh, E. (2010). Consulting Wittgenstein: on the quest to administratively regulate counseling therapists in Canada. Administrative Theory \& Praxis, 32(2), 225-251. doi: 10.2753/ATP10841806320206 
Lyotard, J. F. (2008). A condição pós-moderna (10a ed.). Rio de Janeiro: José Olympio.

Machado-da-Silva, C. L., \& Vizeu, F. (2007). Análise institucional de práticas formais de estratégia. Revista de Administração de Empresas, 47(4), 89-100. doi: 10.1590/S003475902007000400008

Mantere, S. (2010). A Wittgensteinian perspective on strategizing. In D. Golsorkhi, L. Rouleau, D. Seidl, \& E. Vaara (Eds.), Cambridge handbook of strategy as practice (pp. 155-167). Cambridge: Cambridge University Press.

Marcondes, D. (2000). Filosofia, linguagem e comunicação (3a ed. rev. ampl.). São Paulo: Cortez.

Martínez, H. L. (2010). Linguagem e práxis: uma introdução à leitura do "segundo" Wittgenstein (Série Estudos Filosóficos, n. 11). Cascavel: EDUNIOESTE.

Mattos, P. L. C. L. (2001, setembro). Teoria administrativa e pragmática da linguagem: perspectivas para problemas que afligem as relações entre acadêmicos e consultores, educadores e educandos. Anais do Encontro Nacional da Associação Nacional de Pós-Graduação e Pesquisa em Administração, Campinas, SP, Brasil, 25.

Mattos, P. L. C. L. (2003b, setembro). A linguagem da consultoria organizacional: trilhas metodológicas para pesquisa. Anais do Encontro Nacional da Associação Nacional de PósGraduação e Pesquisa em Administração, Atibaia, SP, Brasil, 27.

Mattos, P. L. C. L. (2003a). Teoria administrativa e pragmática da linguagem: perspectivas para problemas que afligem as relações entre acadêmicos e consultores, educadores e educandos. Revista de Administração Contemporânea, 7(2), 35-55. doi: 10.1590/S141565552003000200003

Mattos, P. L. C. L. (2008, setembro). "Administração: ciência ou arte": o que podemos aprender com este mal-entendido. Anais do Encontro Nacional da Associação Nacional de Pós-Graduação e Pesquisa em Administração, Rio de Janeiro, RJ, Brasil, 32.

Mattos, P. L. C. L. (2009). "Administração é ciência ou arte?" O que podemos aprender com este malentendido? Revista de Administração de Empresas, 49(3), 349-360. doi: 10.1590/S003475902009000300009

Mattos, P. L. C. L. (2010, setembro). "Relações teoria-prática" em Administração: o que desaparece nesse "buraco negro". Anais do Encontro Nacional da Associação Nacional de Pós-Graduação e Pesquisa em Administração, Rio de Janeiro, RJ, Brasil, 34.

Mauws, M. K., \& Phillips, N. (1995). Crossroads - Understanding language games. Organization Science, 6(3), 322-334. doi: 10.1287/orsc.6.3.322

Monk, R. (1995). Wittgenstein: o dever do gênio. São Paulo: Companhia das Letras.

Oliveira, M. A. (2006). Reviravolta lingüístico-pragmática na filosofia contemporânea (3a ed.). São Paulo: Edições Loyola.

Orlikowski, W. J., \& Yates, J. (1994). Genre repertoire: the structuring of communicative practices in organizations. Administrative Science Quarterly, 39(4), 541-574.

Powell, T. C. (2001). Competitive advantage: logical and philosophical considerations. Strategic Management Journal, 22(9), 875-888. doi: 10.1002/smj.173

Powell, T. C. (2003). Strategy without ontology. Strategic Management Journal, 24(3), 285-291. doi: $10.1002 / \mathrm{smj} .284$ 
Ran, B., \& Duimering, P. R. (2007). Imaging the organization: language use in organizational identity claims. Journal of Business and Technical Communication, 21(2), 155-187. doi: $10.1177 / 1050651906297167$

Rasche, A., \& Chia, R. (2009). Researching strategy practices: a genealogical social theory perspective. Organization Studies, 30(7), 713-734. doi: 10.1177/0170840609104809

Reed, M. (2005). The agency/structure dilemma in organization theory: open doors and brick walls. In H. Tsoukas \& C. Knudsen (Eds.), The Oxford handbook of organization theory (pp. 289-309). Oxford, England: Oxford University Press.

Rorty, R. (1994). A filosofia e o espelho da natureza (3a ed.). Rio de Janeiro: Relume-Dumará.

Schatzki, T. R. (1996). Social practices: a Wittgensteinian approach to human activity and the social. Cambridge, NY: Cambridge Universitiy Press.

Schatzki, T. R. (1997). Practices and actions a Wittgensteinian critique of Bourdieu and Giddens. Philosophy of the Social Sciences, 27(3), 283-308. doi: 10.1177/004839319702700301

Schatzki, T. R. (2000). Wittgenstein and the social context of an individual life. History of the Human Sciences, 13(1), 93-107. doi: 10.1177/09526950022120629

Schatzki, T. R. (2001). Introduction: practice theory. In T. R. Schatzki, K. Knorr Cetina, \& E. von Savigny (Eds.), The practice turn in contemporary theory (pp. 1-14). London: Routledge.

Shotter, J. (1996). Talk of saying, showing, gesturing, and feeling in Wittgenstein and Vygostky. The Communication Review, 1(4), 471-495. doi: 10.1080/10714429609388275

Shotter, J. (2005). 'Inside the moment of managing': Wittgenstein and the everyday dynamics of our expressive-responsive activities. Organization Studies, 26(1), 113-135. doi: $10.1177 / 0170840605049718$

Shotter, J. (2006). On the edge of social constructionism: Wittgensteinian inquiries into organizations and management. Qualitative Research in Organizations and Management: An International Journal, 1(3), 189-203. doi: 10.1108/17465640610718789

Shotter, J. (2007). Wittgenstein and our talk of feelings in inquiries into the dynamics of language use. International Journal of Critical Psychology, 21, 119-143.

Sluga, H. (1996a). Ludwig Wittgenstein: life and work - an introduction. In H. Sluga \& D. G. Stern (Eds.), The Cambridge companion to Wittgenstein (pp. 1-33). Cambridge, NY: Cambridge University Press.

Sluga, H. (1996b). "Whose house is that?" Wittgenstein on the self. In H. Sluga \& D. G. Stern (Eds.), The Cambridge companion to Wittgenstein (pp. 320-353). Cambridge, NY: Cambridge University Press.

Spaniol, W. (1989). Filosofia e método no segundo Wittgenstein: uma luta contra o enfeitiçamento do nosso entendimento. São Paulo: Loyola.

Valle, B. (2003). Wittgenstein: a forma do silêncio e a forma da palavra (Coleção Filosofia, n. 2). Curitiba: Editora Champagnat.

Van De Ven, A. H., \& Johnson, P. E. (2006). Knowledge for theory and practice. Academy of Management Review, 31(4), 802-821. doi: 10.5465/AMR.2006.22527385

Wittgenstein, L. (2008). Tractatus logico-philosophicus (3a ed.). São Paulo: Editora da Universidade de São Paulo. 
Wittgenstein, L. (2009). Investigações filosóficas (6a ed.). Petrópolis: Vozes.

Yates, J., Orlikowski, W. J., \& Okamura, K. (1999). Explicit and implicit structuring of genres in electronic communication: reinforcement and change of social interaction. Organization Science, 10(1), 83-103. doi: 10.1287/orsc.10.1.83 